\title{
Improved Prediction of Survival by a Risk Factor-Integrating Inflammatory Score in Sorafenib-Treated Hepatocellular Carcinoma
}

\author{
Martin F. Sprinzla, ${ }^{a}$ Martha M. Kirstein ${ }^{f} \quad$ Sandra Koch ${ }^{a, b}$ \\ Marie-Luise Seib ${ }^{a}$ Julia Weinmann-Menke ${ }^{a, b}$ Hauke Lang $^{c}$ \\ Christoph Düber $^{d}$ Gerrit Toenges ${ }^{\mathrm{e}}$ Daniela Zöller ${ }^{\mathrm{e}} \mathrm{h}$ Jens U. Marquardt ${ }^{\mathrm{a}}$ \\ Marcus-Alexander Wörns ${ }^{a}$ Peter R. Galle ${ }^{a} \quad$ Arndt Vogel $^{f} \quad$ Matthias Pinter $^{g}$ \\ Arndt Weinmann ${ }^{a}$, b
}

\begin{abstract}
${ }^{a}$ Department of Internal Medicine I, University Medical Center of the Johannes Gutenberg University Mainz, Mainz, Germany; ${ }^{b}$ Clinical Registry Unit, Department of Internal Medicine I, University Medical Center of the Johannes Gutenberg University Mainz, Mainz, Germany; 'Department of General, Visceral and Transplant Surgery, University Medical Center of the Johannes Gutenberg University Mainz, Mainz, Germany; ${ }^{\mathrm{d} D e p a r t m e n t ~ o f ~ D i a g n o s t i c ~ a n d ~}$ Interventional Radiology, University Medical Center of the Johannes Gutenberg University

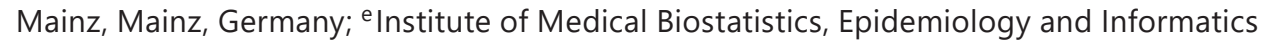
(IMBEI), University Medical Center of the Johannes Gutenberg University Mainz, Mainz, Germany; ${ }^{f}$ Department of Gastroenterology, Hepatology and Endocrinology, Hannover Medical School, Hannover, Germany; ${ }^{9}$ Department of Gastroenterology, Department of Internal Medicine III, Medical University, Vienna, Austria; ${ }^{h}$ Institute for Medical Biometry and Statistics, Faculty of Medicine and Medical Center, University of Freiburg, Freiburg, Germany
\end{abstract}

\section{Keywords}

Hepatocellular carcinoma - Inflammation - Prognostic prediction - Systemic chemotherapy · Sorafenib

\begin{abstract}
Background and Aims: Inflammation affects progression of hepatocellular carcinoma (HCC). We therefore postulate that systemic inflammatory markers could help to predict prognosis in HCC patients receiving sorafenib therapy. Methods: Overall survival (OS) of HCC patients receiving palliative sorafenib treatment was correlated with the neutrophil to lymphocyte ratio (NLR), platelet to lymphocyte ratio (PLR), C-reactive protein to albumin ratio (CAR), Glasgow prognostic score (GPS) and the modified GPS (mGPS) along with clinicopathological parameters. Predictors of OS were assessed by multivariable Cox regression and receiver operating characteristics and area under the curve (ROC-AUC) analyses. Results: Patients receiving sorafenib $(n=120)$ for advanced HCC (Barcelona Clinic Liver Cancer stage C) were explored




\section{Liver Cancer}

\begin{tabular}{|c|c|}
\hline \multicolumn{2}{|l|}{ Liver Cancer 2019;8:387-402 } \\
\hline DOI: 10.1159/000492628 & $\begin{array}{l}\text { (c) } 2018 \text { S. Karger AG, Basel } \\
\text { www.karger.com/lic }\end{array}$ \\
\hline
\end{tabular}

by retrospective analysis. Findings were subsequently validated by a second HCC cohort $(n=$ 113) receiving sorafenib at two independent treatment centers. Multivariable assessment across these HCC cohorts confirmed a stable association of CAR $(p \leq 0.001)$, GPS $(p \leq 0.01)$ and mGPS ( $p \leq 0.004)$ with OS. This study also identified Eastern Cooperative Oncology Group (ECOG) performance score $(p<0.001)$ and portal thrombosis $(p=0.002)$ as prognostic factors and uncovered an inconsistent OS association of NLR and PLR in HCC patients. Additional combined analysis of ECOG, portal thrombosis and GPS within an extended score (GPS-EP) was associated with OS $(p=0.021)$, which was confirmed within the validation cohort $(p=$ 0.001). In sorafenib-treated HCC, the ROC-AUC value for the prediction of 12-month survival was 0.761 (CAR $>/ \leq 0.37$ cut-off, $p<0.001$ ), 0.766 (GPS, $p<0.001$ ) and 0.754 (mGPS, $p<0.001$ ), respectively. In comparison to this, GPS-EP achieved a higher AUC of $0.826(0.746-0.907)$ for the 12 -month survival prediction, resulting in a $64.4 \%$ sensitivity and $83.3 \%$ specificity at a $>2$ point cut-off. Conclusions: Inflammatory scores obtained before sorafenib treatment initiation are associated with OS in advanced HCC. Their combination with other risk factors improves prediction of 3- and 12-month survival, which could guide treatment decisions in selected patient subgroups.

(C) 2018 S. Karger AG, Basel

\section{Introduction}

Response to sorafenib treatment of hepatocellular carcinoma (HCC) remains unpredictable despite efforts to define prognosis by clinical stages. As the inflammatory environment in HCC contributes to tumor progression, inflammatory markers may improve assessment of treatment-related prognosis. The prognostic role of inflammation in HCC is supported by the elevation of cytokine levels in HCC patients as well as by the observation of inflammatory cell infiltration at the HCC invasion front, both correlating with HCC progression and increased recurrence rates after HCC resection [1-3].

Different inflammatory markers have been proposed in the past, incorporating quantification of circulating leucocytes and acute phase proteins to predict tumor prognosis. Neutrophilic granulocytes have been assessed, as they are recruited into tumor tissue and become activated in the presence of tumor-derived factors. Furthermore, they respond to hypoxic conditions and tissue necrosis which are commonly observed in solid tumor tissue [4]. Besides tumor-infiltrating granulocytes, which suppress anti-tumor immune surveillance [5], circulating granulocytes are also associated with prognosis in different tumor types [6-8].

Another established inflammation marker, which predominantly originates directly from the liver, is the acute-phase C-reactive protein (CRP) $[9,10]$. CRP expression is tightly linked to JAK/STAT-3- and NF-kB-dependent signaling [11-13], both of which are known drivers of tumor-associated inflammation [14-16]. In HCC patients, the CRP serum concentrations correlate with apoptotic cell turnover measured by circulating caspase cleavage products [3]. Tumor-associated myeloid cells sensing apoptosis provide a mechanistic link for this observation [17] as their apoptosis-driven activation leads to constitutive STAT-3 induction and persistent procarcinogenic inflammation [18].

The established inflammatory scores can be obtained from standard laboratory parameters and have been assessed in different malignant entities [19]. As the inflammatory markers are corrected for liver function and sequestration of circulating blood cells by hypersplenism, they also incorporate effects of liver cirrhosis and portal hypertension. Commonly used inflammation scores are the neutrophil to lymphocyte ratio (NLR) [20-23], platelet to lymphocyte ratio (PLR) [20], CRP to albumin ratio (CAR) [24], the Glasgow prognostic score (GPS) [25] as well as the modified GPS (mGPS) [19]. In patients suffering from HCC, the inflam- 


\section{Liver Cancer}

\begin{tabular}{l|l}
\hline Liver Cancer 2019;8:387-402 \\
\hline DOI: 10.1159/000492628 & $\begin{array}{l}\text { (c) 2018 S. Karger AG, Basel } \\
\text { www.karger.com/lic }\end{array}$ \\
\hline
\end{tabular}

Sprinzl et al.: Extended Prognostic Inflammatory Score for HCC

matory scores were evaluated to predict survival in patients receiving resection $[23,26,27]$, local tumor ablation [21] and systemic therapy [28, 29].

However, there is a lack of data evaluating different inflammatory scores as prognostic markers to guide palliative treatment decisions for sorafenib in HCC patients. To clarify the impact of inflammation on sorafenib response, we explored inflammatory scores in advanced HCC (Barcelona Clinic Liver Cancer [BCLC] stage C) and validated our findings in an independent HCC cohort treated with sorafenib. Aiming for a more precise prediction of overall survival (OS), we also evaluated the combination of clinicopathological factors and inflammatory scores to identify superior scoring systems.

\section{Patients and Methods}

\section{Patient Population}

We assessed prognostic parameters in HCC patients with confirmed diagnosis based on radiological and laboratory criteria according to EASL-EORTC guidelines [29]. A confirmative HCC diagnosis by histopathological examination was available in $54.1 \%$.

HCC patients at the University Medical Center, Mainz (Germany), who started palliative sorafenib monotherapy between 2007 and 2013 were explored. We identified 143 patients with sorafenib monotherapy providing sufficient data to investigate prognostic variables. After exclusion of 2 patients receiving sorafenib as a bridging treatment prior to orthotopic liver transplantation, a total of 141 patients were assessed. Subsequently, patients receiving palliative sorafenib therapy at the Hannover Medical School, Germany $(n=64)$, and at the Medical University, Vienna, Austria $(n=108)$, were analyzed as an independent sorafenib cohort $(n=172)$.

From the two independent data sets (Mainz and Hannover/Vienna), we further selected patients with BCLC-C stage HCC, who received sorafenib according to current treatment guidelines. These patients are reported in the main text as exploration cohort $(n=120)$ and validation cohort $(n=113)$, respectively. Analyses of the complete cohorts, covering all BCLC stages, are included in the supplemental data section (for all online suppl. material, see www.karger.com/doi/10.1159/492628).

Baseline characteristics were obtained for the time-point of sorafenib treatment initiation. Assessment included standardized performance scores (Eastern Cooperative Oncology Group, ECOG) [30], ChildTurcotte-Pugh (CTP) cirrhosis stage [31] and oncological BCLC stages [32] based on clinical, laboratory and radiological findings. CAR, Glasgow prognosis score (GPS) and modified Glasgow prognosis score (mGPS) as well as a combined GPS, ECOG performance and portal thrombosis score (e.g., GPS-EP) were calculated for each patient (Table 1). The NLR and PLR were also calculated for each patient with the exception of 71 patients from the sorafenib validation cohort who had undetermined differential blood counts at baseline. Cut-off values for PLR, CAR and NLR were applied as published previously [20, 24].

All patients received clinical, laboratory and radiological assessments as well as observation of OS until December 31,2014, resulting in a median follow-up of 5.5 months (range 0.2-89.9 months) and 7.0 months (range 0.1-83.0 months) within the sorafenib exploration and validation cohorts, respectively. Radiological staging by CT scan was routinely performed at a median interval of 66 days and analyzed according to RECIST criteria. Progression-free survival (PFS) was assessed as defined by the time from sorafenib initiation to disease progression or death from any cause. Following this assessment, PFS was available in $88.3 \%(n=$ $106 / 120)$ of the exploration cohort and in $62.8 \%(n=71 / 113)$ patients of the validation cohort. This retrospective study was approved by the institutional ethics boards.

\section{Data Management and Statistical Analysis}

Clinical data and radiological findings were retrieved from patient charts. Laboratory parameters (standard values) such as leukocyte count $(3.5-10 / \mathrm{hL})$, thrombocyte count $(150-360 / \mathrm{nL})$, total bilirubin (0.2-1.2 mg/dL), serum albumin (34-48 g/L), prothrombin time/Quick (70-120\%) and CRP (<5 mg/L) were obtained from the laboratory information management programs of the different study sites at given time points. All data were collected and analyzed at the clinical registry unit at Mainz University [33].

Explorative comparisons between independent groups were performed using the Mann-Whitney U test and Kruskal-Wallis test as indicated. 
Table 1. Inflammatory scoring systems

\begin{tabular}{llll}
\hline Variable & $\begin{array}{l}\text { GPS } \\
\text { (score 0-2) }\end{array}$ & $\begin{array}{l}\text { mGPS } \\
\text { (score 0-2) }\end{array}$ & $\begin{array}{l}\text { GPS-EP } \\
\text { (score 0-6) }\end{array}$ \\
\hline Alb $>35$ g/L and CRP $<10 \mathrm{mg} / \mathrm{L}$ & 0 & 0 & 0 \\
Alb $<35$ g/L and CRP $<10 \mathrm{mg} / \mathrm{L}$ & 1 & 0 & 1 \\
Alb $>35$ g/L and CRP $>10 \mathrm{mg} / \mathrm{L}$ & 1 & 1 & 1 \\
Alb $<35$ g/l and CRP $>10 \mathrm{mg} / \mathrm{L}$ & 2 & 2 & 2 \\
\hline Plus & & & \\
Portal thrombosis & NR & NR & 1 \\
\hline Plus & & & \\
ECOG Score 0 & NR & NR & 0 \\
ECOG Score 1 & NR & NR & 1 \\
ECOG Score 2 & NR & NR & 2 \\
ECOG Score 3 & NR & NR & 3 \\
\hline
\end{tabular}

CRP, C-reactive-protein; Alb, albumin; GPS, Glasgow prognostic score; mGPS, modified Glasgow prognostic score; GPS-EP, ECOG/portal thrombosis-extended Glasgow prognostic score; NR, not rated. Addition of the individual scoring categories results in the total GPS-EP scoring value. Each factor in the GPS-EP score is weighted equally.

Survival depending on baseline risk factors and inflammatory scores was calculated using the KaplanMeier method and log rank test. Prognostic markers for OS previously indicated by univariable analysis $(p \leq$ 0.100 ) were subjected to a multivariable Cox proportional hazard model. Multivariable analyses of inflammatory scores (CAR, GPS, mGPS), which share the same variables, were calculated individually along with all other prognostic variables. For the covariables not related to the inflammatory scores, the $p$ values derived from the multivariable analysis of CAR are shown.

Receiver operating characteristics (ROC) and area under the curve (AUC) were finally calculated for prognostic factors confirmed by multivariable Cox regression. A comparative analysis to determine the discriminatory ability of each prognostic score was based on the method established by DeLong et al. [34]. Sensitivity and specificity to predict OS by discrete cut-offs were identified, and the corresponding $95 \%$ confidence intervals were calculated (Wilson score). A two-sided $p$ value of less than 0.05 was defined as significant for all applied statistical tests. Statistical tests were calculated with SPSS v24 (SPSS Inc., Chicago, IL, USA) and graphics were edited by Adobe Illustrator (Adobe Systems Inc., San Jose, CA, USA).

\section{Results}

\section{Patient Characteristics}

Baseline patient characteristics were assessed for the sorafenib exploration and validation cohorts showing BCLC-C stage HCC (Table 2). The leading liver disease entities were alcoholic liver disease followed by chronic hepatitis $\mathrm{C}$, chronic hepatitis $\mathrm{B}$ and non-alcoholic steatohepatitis. Although these liver disease entities were equally distributed among both cohorts, a significantly lower rate of liver cirrhosis $(p=0.008)$, portal thrombosis $(p=0.008)$ and thrombopenia $(p<0.001)$ was identified in the exploration cohort compared to the validation cohort.

A median OS of 6.2 months (range 0.2-89.9) and 8.2 months (range 0.0-83.0) was observed for the sorafenib exploration and validation cohorts, respectively. The corresponding median PFS, as identified by radiological staging, was 3.38 months (range 2.294.47 ) in the exploration cohort and 5.38 months (range 3.56-7.20) in the validation cohort. 
Table 2. Baseline characteristics of BCLC-C stage HCC patients

\begin{tabular}{|c|c|c|}
\hline Patient characteristics & $\begin{array}{l}\text { Exploration cohort } \\
(n=120)\end{array}$ & $\begin{array}{l}\text { Validation cohort } \\
(n=113)\end{array}$ \\
\hline Age, years & $65.5(24.2-82.0)$ & $66.0(36.0-86.0)$ \\
\hline \multicolumn{3}{|l|}{ Gender } \\
\hline Male & $106(88.3)$ & $93(82.3)$ \\
\hline Female & 14 (11.7) & $20(17.7)$ \\
\hline \multicolumn{3}{|l|}{ Etiology of liver disease } \\
\hline Alcohol & $34(28.2)$ & $41(36.3)$ \\
\hline Hepatitis C & $25(20.8)$ & $27(23.9)$ \\
\hline Hepatitis B & $23(19.2)$ & $13(11.5)$ \\
\hline NASH & $11(9.2)$ & $13(11.5)$ \\
\hline Hemochromatosis & $2(1.7)$ & $3(2.7)$ \\
\hline Other liver disease & $2(1.6)$ & $1(0.9)$ \\
\hline Cryptogenic liver cirrhosis & $7(5.8)$ & $8(7.1)$ \\
\hline Unknown & $16(13.3)$ & $8(7.1)$ \\
\hline \multicolumn{3}{|l|}{ Liver cirrhosis } \\
\hline No & $36(30.0)$ & $16(14.2)$ \\
\hline Yes & $84(70.0)$ & $97(85.8)$ \\
\hline \multicolumn{3}{|l|}{ Child-Turcotte-Pugh score } \\
\hline A & $31(25.8)$ & $41(36.3)$ \\
\hline B & $53(44.2)$ & $56(49.6)$ \\
\hline \multicolumn{3}{|l|}{ Portal thrombosis } \\
\hline No & $79(65.8)$ & $53(46.9)$ \\
\hline Yes & $41(34.2)$ & $60(53.1)$ \\
\hline Progression-free survival, months & $3.38(2.29-4.47)$ & $5.38(3.56-7.20)$ \\
\hline Overall survival, months & $6.2(0.2-89.9)$ & $8.2(0.0-83.0)$ \\
\hline 3-month survival & $91(75.8)$ & $93(82.3)$ \\
\hline 6-month survival & $61(50.8)$ & $68(60.2)$ \\
\hline 12-month survival & $30(25.0)$ & $40(35.4)$ \\
\hline \multicolumn{3}{|l|}{ ECOG score } \\
\hline 0 & $28(23.3)$ & $34(30.1)$ \\
\hline 1 & $68(69.2)$ & $66(58.4)$ \\
\hline 2 & $9(7.5)$ & $13(11.5)$ \\
\hline \multicolumn{3}{|l|}{ BCLC classification } \\
\hline $\mathrm{C}$ & $120(100)$ & $113(100)$ \\
\hline \multicolumn{3}{|l|}{ Extrahepatic metastasis } \\
\hline No & $35(29.5)$ & $63(55.8)$ \\
\hline Yes & $85(70.8)$ & $50(44.2)$ \\
\hline Maximum tumor diameter, $\mathrm{cm}$ & $6.9(1.0-14.0)$ & $5.2(1.2-14.0)$ \\
\hline \multicolumn{3}{|c|}{ Active treatment modalities before sorafenib } \\
\hline None & $49(40.8)$ & $56(49.4)$ \\
\hline 1 & $49(40.8)$ & $38(33.6)$ \\
\hline 2 & $18(15.0)$ & $12(10.6$ \\
\hline$>2$ & $4(3.3)$ & $7(6.2)$ \\
\hline \multicolumn{3}{|l|}{ Baseline laboratory parameters } \\
\hline $\mathrm{AFP}, \mathrm{U} / \mathrm{L}$ & $138(1-336,900)$ & $51.9(1-53,419)$ \\
\hline Total bilirubin, mg/dL & $1.0(0.1-6.1)$ & $1.1(0.2-3.9)$ \\
\hline Albumin, $\mathrm{g} / \mathrm{L}$ & $31(13-50)$ & $34(22-47)$ \\
\hline $\mathrm{CRP}, \mathrm{mg} / \mathrm{L}$ & $18(0.7-271)$ & $14(0-150)$ \\
\hline Leukocytes, cells/nL & $6.5(2.0-19.8)$ & $5.2(1.9-14.5)$ \\
\hline Thrombocytes, cells/nL & $206(42-680)$ & $148(34-514)$ \\
\hline
\end{tabular}


Table 2 (continued)

\begin{tabular}{|c|c|c|}
\hline Patient characteristics & $\begin{array}{l}\text { Exploration cohort } \\
(n=120)\end{array}$ & $\begin{array}{l}\text { Validation cohort } \\
(n=113)\end{array}$ \\
\hline \multicolumn{3}{|c|}{ Baseline inflammatory scores } \\
\hline $\mathrm{NLR}^{\#}$ & $3.7(1.1-19.9)$ & $3.7(1.2-14.2)$ \\
\hline \multicolumn{3}{|l|}{ NLR group $\#$} \\
\hline$<5$ & $79(65.8)$ & $47(74.6)$ \\
\hline$\geq 5$ & $41(34.2)$ & $16(25.4)$ \\
\hline $\mathrm{PLR}^{\#}$ & $177.9(25.8-726.5)$ & $134.2(37.5-682)$ \\
\hline \multicolumn{3}{|l|}{ PLR group $\#$} \\
\hline$<150$ & $44(36.7)$ & $33(52.4)$ \\
\hline $150-300$ & $51(42.5)$ & $19(30.2)$ \\
\hline$>300$ & $25(20.8)$ & $11(17.5)$ \\
\hline CAR & $0.55(0.02-16.25)$ & $0.42(0.01-4.94)$ \\
\hline \multicolumn{3}{|l|}{ CAR group } \\
\hline$<0.37$ & $45(37.5)$ & $53(46.9)$ \\
\hline$\geq 0.37$ & $75(62.5)$ & $60(53.1)$ \\
\hline \multicolumn{3}{|l|}{ GPS } \\
\hline 0 & $19(15.8)$ & $31(27.4)$ \\
\hline 1 & $36(30.0)$ & $35(31.0)$ \\
\hline 2 & $65(54.2)$ & $47(41.6)$ \\
\hline \multicolumn{3}{|l|}{ mGPS } \\
\hline 0 & $40(33.3)$ & $49(43.5)$ \\
\hline 1 & $15(12.5)$ & $17(15.0)$ \\
\hline 2 & $65(54.2)$ & $47(41.6)$ \\
\hline \multicolumn{3}{|l|}{ GPS-EP } \\
\hline 0 & $11(9.2)$ & $6(5.3)$ \\
\hline 1 & $24(20.0)$ & $20(17.7)$ \\
\hline 2 & $22(18.3)$ & $25(22.1)$ \\
\hline 3 & $36(30.0)$ & $41(36.3)$ \\
\hline 4 & $24(20.0)$ & $17(15.0)$ \\
\hline 5 & $3(2.5)$ & $4(3.5)$ \\
\hline 6 & - & - \\
\hline
\end{tabular}

Data are presented as median (range) or $n$ (\%). BCLC, Barcelona Clinic Liver-Cancer; AFP, alpha-fetoprotein; AST, aspartate-aminotransferase; ALT, alanine-aminotransferase; INR, international normalized ratio; CRP, C-reactive protein; GPS, Glasgow prognostic score; mGPS, modified Glasgow prognostic score; GPS-EP, ECOG/portal thrombosis-extended Glasgow prognostic score; PLR, platelet to lymphocyte ratio; NLR, neutrophil to leukocyte ratio; CAR, C-reactive protein to albumin ratio. Baseline variables were assessed at the time point of sorafenib treatment initiation in BCLC-C stage HCC patients for both cohorts as indicated. \# NLR and PLR were determined for 101 patients in the sorafenib validation cohort.

\section{Characteristics of Oncological Therapy}

Oncological treatment history was assessed in the exploration and validation cohorts receiving sorafenib therapy for BCLC-C stage HCC. The exploration cohort received standarddose sorafenib (400 mg, b.i.d.) monotherapy for a median of 154 days (range 6-977 days), and the validation cohort underwent the same treatment for a median of 162 days (range $1-1,916$ days).

Other oncological interventions were performed in 59.2\% $(n=80 / 120)$ and in 50.4\% ( $n=57 / 113$ ) prior to palliative sorafenib treatment, respectively. Transarterial chemoembolization and HCC resection were the most common oncological interventions. Orthotopic liver transplantation was conducted in $11(9.2 \%)$ and $6(5.3 \%)$ patients prior to palliative sorafenib treatment, respectively. As part of a complex multimodal treatment approach, more than two 


\section{Liver

Sprinzl et al.: Extended Prognostic Inflammatory Score for HCC

different treatment modalities were applied in 4 (3.3\%) and 7 (6.2\%) patients, respectively, prior to palliative sorafenib administration. An overview of all treatment modalities is shown in online supplementary Table 2.

\section{Inflammatory Scores}

Inflammatory scores are listed for the exploration and validation cohorts with BCLC-C stage HCC disease (Table 2). In the exploration cohort, systemic inflammation was reflected by elevated CRP in $82.5 \%(n=99 / 120)$, whereas leukocyte counts at baseline typically remained within the normal limits in $89.2 \%(n=107 / 120)$. The exploration cohort showed a median NLR of 3.7 (range 1.1-19.9), PLR of 177.9 (range 25.8-726.5) and CAR of 0.55 (range $0.02-16.25)$. Changes in albumin and CRP concentrations resulted in a positive GPS in $84.5 \%$ $(n=101 / 120)$ and mGPS in $66.7 \%(n=80 / 120)$, defined by a score of $\geq 1$ point.

In the validation cohort, CRP levels were typically elevated in $80.5 \%(n=91 / 113)$, whereas leukocyte counts remained within normal limits in $90.3 \%(n=102 / 113)$. The validation cohort showed a median NLR of 3.7 (range 1.2-14.1), PLR of 134.2 (range 37.5-682) and CAR of 0.42 (range $0.01-4.94$ ). The GPS and mGPS scores were positive ( $\geq 1$ point) in $72.6 \%(n=82 / 113)$ and $56.6 \%(n=64 / 113)$, respectively. No differences in median NLR and CAR values $(p>0.05)$ were identified between both cohorts, whereas PLR, GPS and mGPS scores were higher in the exploration cohort $(p<0.05)$.

\section{Prognostic Factors}

Prognostic factors were analyzed in BCLC-C stage HCC patients, who received sorafenib treatment in concordance with current treatment guidelines [32]. Assessment of the exploration cohort identified CTP stage, ECOG score, portal vein thrombosis, total bilirubin and no oncological treatment before sorafenib as clinicopathological risk factors for a reduced OS by univariable analysis. An association between inflammation and OS was also observed for NLR and CAR according to previously published cut-offs [24,35] and based on GPS and mGPS (Table 3).

In the validation cohort, all risk factors were confirmed, with the exception of oncological pre-treatment status and portal thrombosis. Assessment of the validation cohort also supported CAR, GPS and mGPS, whereas NLR and PLR were not consistently associated with OS (Table 3).

We proceeded with a combined exploration of HCC patients showing no CTP stage B cirrhosis derived from both cohorts $(n=124)$, as this subgroup is known to have the highest benefit from palliative sorafenib treatment [36, 37]. Following this selection, the association of GPS (log rank, $p<0.001$ ), mGPS (log rank, $p<0.001$ ), CAR (log rank, $p<0.001$ ) and NLR (log rank, $p=0.007$ ) with OS was confirmed by univariable assessment.

Eventually, we explored the association of inflammatory scores with PFS in radiologically staged patients $(n=97)$ from both cohorts, showing no CTP stage B cirrhosis. Also, this analysis indicated an association of CAR (log rank, $p<0.001)$, GPS (log rank $p<0.001)$ and mGPS (log rank $\mathrm{p}<0.001$ ) with PFS, whereas NLR (log rank, $\mathrm{p}=0.532)$ and PLR (log rank, $p=0.397$ ) were not significantly linked to treatment response.

Following the first exploration, we added a multivariable analysis in BCLC-C stage HCC patients to confirm our findings. Multivariate COX regression of the exploration cohort verified ECOG $(p<0.001)$, portal vein thrombosis $(p<0.001)$, CAR $(p<0.001)$, GPS $(p=0.010)$ and mGPS ( $p=0.004)$ as independent risk factors for poor survival. Multivariable analysis of the validation cohort supported portal thrombosis along with CAR, GPS and mGPS as risk factors but did not associate ECOG score with survival, whereas viral etiology did affect outcome (Table 4). The corresponding uni- and multivariable analyses of unselected HCC patients from both cohorts are summarized in online supplementary Table 3 and 4 . 
Table 3. Survival analysis and univariable risk factor assessment in BCLC-C stage HCC patients

\begin{tabular}{|c|c|c|c|c|}
\hline \multirow[t]{2}{*}{ Variable } & \multicolumn{2}{|c|}{ Exploration cohort $(n=120)$} & \multicolumn{2}{|c|}{ Validation cohort $(n=113)$} \\
\hline & $\begin{array}{l}\text { survival, months } \\
\text { median }(95 \% \mathrm{CI})\end{array}$ & $\begin{array}{l}\log \text { rank } \\
p \text { value }\end{array}$ & $\begin{array}{l}\text { survival, months } \\
\text { median }(95 \% \mathrm{CI})\end{array}$ & $\begin{array}{l}\log \text { rank } \\
p \text { value }\end{array}$ \\
\hline \multicolumn{5}{|l|}{ Gender } \\
\hline Female & $6.0(4.8-7.2)$ & 0.309 & $5.4(2.2-8.6)$ & 0.306 \\
\hline Male & $6.9(1.1-12.7)$ & & $9.0(5.7-12.3)$ & \\
\hline \multicolumn{5}{|l|}{ Liver cirrhosis } \\
\hline No & $7.4(5.6-9.2)$ & 0.077 & $11.9(9.0-14.8)$ & 0.722 \\
\hline Yes & $5.5(4.1-6.9)$ & & $7.8(5.1-10.4)$ & \\
\hline \multicolumn{5}{|c|}{ Child-Turcotte-Pugh stage } \\
\hline No cirrhosis & $7.4(5.6-9.2)$ & 0.005 & $11.9(9.0-14.8)$ & 0.014 \\
\hline A & $10.4(7.7-13.1)$ & & $11.3(8.0-14.5)$ & \\
\hline $\mathrm{B}$ & $4.3(3.6-4.9)$ & & $6.0(4.6-7.4)$ & \\
\hline $\mathrm{C}$ & $6.1(4.8-7.4)$ & & - & \\
\hline \multicolumn{5}{|l|}{ ECOG score } \\
\hline 0 & $10.7(6.3-15.1)$ & $<0.001$ & $7.8(4.3-11.2)$ & 0.004 \\
\hline 1 & $6.5(5.1-7.9)$ & & $10.0(7.0-13.0)$ & \\
\hline 2 & $2.2(1.7-2.7)$ & & $5.0(2.4-7.6)$ & \\
\hline 3 & NR & & - & \\
\hline 4 & - & & - & \\
\hline \multicolumn{5}{|c|}{ Portal thrombosis } \\
\hline No & $7.8(5.6-10.2)$ & $<0.001$ & $10.0(6.8-13.2)$ & 0.665 \\
\hline Yes & $3.9(3.0-4.7)$ & & $6.0(4.1-7.9)$ & \\
\hline \multicolumn{5}{|c|}{ Extrahepatic HCC metastasis } \\
\hline No & $4.4(3.2-5.6)$ & 0.562 & $8.5(4.9-12.2)$ & 0.257 \\
\hline Yes & $6.9(5.4-8.4)$ & & $6.5(3.5-9.5)$ & \\
\hline \multicolumn{5}{|c|}{ Etiology of liver disease } \\
\hline Non-viral & $5.3(4.0-6.7)$ & 0.084 & $10.0(5.7-14.3)$ & 0.135 \\
\hline Viral & $7.5(5.5-9.4)$ & & $6.0(4.2-7.8)$ & \\
\hline \multicolumn{5}{|c|}{ Oncologic treatment before sorafenib } \\
\hline No & $4.9(3.0-6.7)$ & 0.008 & $5.4(2.1-8.7)$ & 0.205 \\
\hline Yes & $8.2(5.2-11.2)$ & & $10.0(7.5-12.5)$ & \\
\hline \multicolumn{5}{|l|}{ Total bilirubin } \\
\hline$\leq 1.2 \mathrm{~g} / \mathrm{dL}$ & $7.8(5.3-10.3)$ & 0.004 & $11.3(8.4-14.2)$ & 0.008 \\
\hline$>1.2 \mathrm{~g} / \mathrm{dL}$ & $3.9(2.9-4.9)$ & & $5.4(3.9-7.0)$ & \\
\hline \multicolumn{5}{|l|}{ ALT } \\
\hline$<2 \times U N L$ & $6.7(5.3-8.1)$ & 0.302 & $8.2(5.5-10.8)$ & 0.517 \\
\hline$\geq 2 \times \mathrm{UNL}$ & $3.8(2.3-5.4)$ & & $6.0(0.3-11.7)$ & \\
\hline \multicolumn{5}{|l|}{ Thrombocytes } \\
\hline$<100 / \mathrm{nL}$ & $5.5(4.2-6.8)$ & 0.406 & $7.0(3.6-10.4)$ & 0.978 \\
\hline$\geq 100 / \mathrm{nL}$ & $9.3(4.2-14.5)$ & & $8.9(4.5-13.3)$ & \\
\hline \multicolumn{5}{|l|}{ NLR } \\
\hline$<5$ & $10.4(5.7-15.1)$ & 0.002 & $9.8(7.3-12.2)$ & 0.062 \\
\hline$\geq 5$ & $5.0(4.1-5.9)$ & & $6.1(5.2-7.1)$ & \\
\hline \multicolumn{5}{|l|}{ PLR } \\
\hline$<150$ & $7.0(5.3-8.6)$ & 0.159 & $9.8(7.6-11.9)$ & 0.161 \\
\hline $150-300$ & $6.7(4.5-8.9)$ & & $6.5(0.0-13.5)$ & \\
\hline$>300$ & $4.3(2.1-6.4)$ & & $6.1(1.0-11.3)$ & \\
\hline
\end{tabular}




\section{Liver Cancer}

\begin{tabular}{l|l}
\hline Liver Cancer 2019;8:387-402 \\
\hline DOI: 10.1159/000492628 & $\begin{array}{l}\text { @) 2018 S. Karger AG, Basel } \\
\text { www.karger.com/lic }\end{array}$ \\
\hline
\end{tabular}

Sprinzl et al.: Extended Prognostic Inflammatory Score for HCC

Table 3 (continued)

\begin{tabular}{|c|c|c|c|c|}
\hline \multirow[t]{2}{*}{ Variable } & \multicolumn{2}{|c|}{ Exploration cohort $(n=120)$} & \multicolumn{2}{|c|}{ Validation cohort $(n=113)$} \\
\hline & $\begin{array}{l}\text { survival, months } \\
\text { median }(95 \% \mathrm{CI})\end{array}$ & $\begin{array}{l}\log \text { rank } \\
p \text { value }\end{array}$ & $\begin{array}{l}\text { survival, months } \\
\text { median }(95 \% \mathrm{CI})\end{array}$ & $\begin{array}{l}\text { log rank } \\
p \text { value }\end{array}$ \\
\hline \multicolumn{5}{|l|}{ CAR } \\
\hline$<0.37$ & $12.4(7.7-17.2)$ & $<0.001$ & $11.9(8.7-15.1)$ & $<0.001$ \\
\hline$\geq 0.37$ & $4.7(3.7-5.7)$ & & $5.0(3.4-6.6)$ & \\
\hline \multicolumn{5}{|l|}{ GPS } \\
\hline 0 & $17.1(10.9-23.4)$ & $<0.001$ & $16.0(9.5-22.5)$ & $<0.001$ \\
\hline 1 & $7.0(6.0-7.9)$ & & $7.0(2.0-12.0)$ & \\
\hline 2 & $4.2(3.5-4.9)$ & & $5.4(3.1-7.6)$ & \\
\hline \multicolumn{5}{|l|}{ mGPS } \\
\hline 0 & $11.6(7.2-16.0)$ & $<0.001$ & $11.9(8.2-15.6)$ & $<0.001$ \\
\hline 1 & $6.7(4.3-9.1)$ & & $9.8(0.0-21.9)$ & \\
\hline 2 & $4.2(3.5-4.9)$ & & $5.4(3.1-7.6)$ & \\
\hline \multicolumn{5}{|l|}{ GPS-EP } \\
\hline 0 & $30.35(8.83-51.88)$ & $<0.001$ & $16.0(2.2-29.8)$ & $<0.001$ \\
\hline 1 & $13.51(8.26-18.76)$ & & $11.9(9,4-14.4)$ & \\
\hline 2 & $6.27(4.52-8.01)$ & & $13.0(7.2-18.8)$ & \\
\hline 3 & $5.23(4.65-5.82)$ & & $6.5(3.2-9.7)$ & \\
\hline 4 & $2.47(2.03-2.91)$ & & $5.4(3.5-7.3)$ & \\
\hline 5 & $1.47(0.30-2.64)$ & & $2.0(5.3-11.1)$ & \\
\hline 6 & - & & - & \\
\hline
\end{tabular}

ALT, alanine-aminotransferase; UNL, upper normal limits; PLR, platelet to lymphocyte ratio; NLR, neutrophil to leukocyte ratio; CAR, C-reactive protein to albumin ratio; GPS, Glasgow prognostic score; mGPS, modified Glasgow prognostic score; mGPS-EP, ECOG/portal thrombosis-extended modified Glasgow prognosis score; NR, not rated. Baseline variables were assessed at the time point of sorafenib treatment initiation in BCLC-C stage HCC patients for both cohorts as indicated. Kaplan-Meier analysis, log rank test, $p$ value across all strata.

\section{Risk Factor-Integrating Inflammatory Score}

Throughout our search for a superior prognostic score, we identified ECOG performance stage and presence of portal thrombosis as risk factors in our exploration cohort along with selected inflammatory scores. Therefore, ECOG stage and presence of portal thrombosis were incorporated into the GPS score, which was then named GPS-EP score (Table 1). GPS-EP proved to be a reliable prognostic score throughout the two HCC cohorts under palliative sorafenib therapy (Fig. 1; Table 3). GPS-EP was also associated with OS (log rank, $p<0.001$ ) and PFS (log rank, $p<0.001$ ) in selected HCC patients showing no advanced CTP stage B cirrhosis from both cohorts. The association of GPS-EP with OS was eventually confirmed by multivariable analysis (Table 4).

\section{Survival Prediction by Inflammatory Scores}

We finally compared inflammatory scores to predict survival by ROC-AUC analysis in BCLC-C stage HCC patients (online suppl. Table 5b). In the exploration population, a marginal AUC for 3-month survival, ranging from 0.630 to $0.696(p<0.05)$, was calculated for baseline NLR, CAR, GPS and mGPS. Further assessment of the validation cohort only revealed a marginal AUC value (0.677, $p=0.051$ ) to predict 3-month survival for GPS (Fig. 2). 


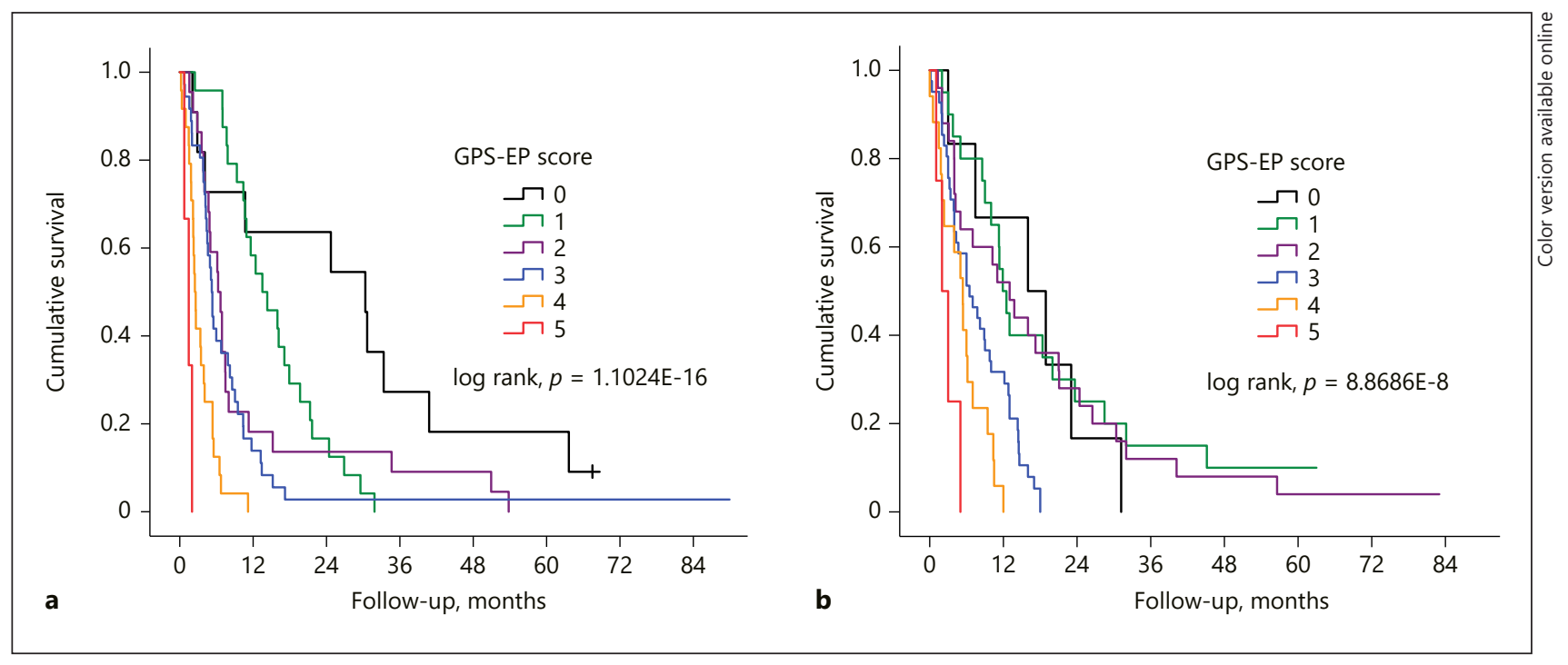

Fig. 1. Overall survival according to the ECOG/portal thrombosis-extended Glasgow prognosis score (GPSEP) risk stratification. Survival analysis was performed for the exploration cohort ( $n=120)$ (a) and the validation cohort $(n=113)$ (b) receiving sorafenib treatment for BCLC-C stage HCC. Overall survival was stratified for the proposed GPS-EP score and compared by log rank analysis at a significance level of $p \leq 0.05$.

Compared to all other inflammatory scores, the GPS-EP score achieved a better 3-month survival prediction within the exploration cohort (AUC: $0.768 ; p<0.001$ ) and within the validation cohort (AUC: $0.775 p=0.002$ ) (Fig. 2). This translated into a useful prediction of 3 -month mortality at a GPS-EP cut-off $>3$ for the exploration cohort (specificity $89 \%$, sensitivity 59\%) and for the validation cohort (specificity $86 \%$, sensitivity $35 \%$ ).

Satisfactory AUC values of $0.826(p<0.001)$ and $0.798(p<0.001)$ were also observed for GPS-EP to predict 12-month survival in the exploration cohort, respectively. This resulted in a specificity of $83.3 \%$ and sensitivity of $64.4 \%$ at a GPS-EP cut-off $>2$ to predict 12 -month survival, whereas in the validation cohort the same GPS-EP cut-off achieved a specificity of $67.5 \%$ and a sensitivity of $65.8 \%$ (online suppl. Table 6 ). Again, the other inflammatory scores revealed inferior AUC values (online suppl. Table $5 \mathrm{a} / \mathrm{b}$ ), of which only CAR ( $>0.37$ ) provided a satisfactory specificity of $76.7 \%$ and a sensitivity of $75.6 \%$ to predict 12 -month survival (online suppl. Table 6).

\section{Discussion}

The inflammation-based scores CAR, GPS and mGPS demonstrated prognostic usefulness in independent European collectives of HCC patients treated with sorafenib. Throughout these cohorts, the CRP-based scores were superior for prognostic stratification compared to cell frequency-based inflammation scores such as NLR and PLR. Prediction of OS rates was further improved by incorporating ECOG performance score, presence of portal thrombosis and GPS into one novel scoring system (GPS-EP).

As this report is based on central European HCC cohorts, we only included a limited number of HBV-and non-alcoholic steatohepatitis-associated HCC. The consistency of underlying liver disease among the different cohorts, however, indicates a representative patient composition monitored over a long period of time. 


\section{Liver Cancer}

\begin{tabular}{|c|c|}
\hline \multicolumn{2}{|c|}{ Liver Cancer 2019;8:387-402 } \\
\hline DOI: 10.1159/000492628 & $\begin{array}{l}\text { (c) } 2018 \text { S. Karger AG, Basel } \\
\text { www.karger.com/lic }\end{array}$ \\
\hline
\end{tabular}

Sprinzl et al.: Extended Prognostic Inflammatory Score for HCC

Table 4. Multivariable risk factor assessment in BCLC-C stage HCC patients

\begin{tabular}{|c|c|c|c|c|}
\hline \multirow[t]{2}{*}{ Variable } & \multicolumn{2}{|l|}{$\begin{array}{l}\text { Exploration cohort } \\
(n=120)\end{array}$} & \multicolumn{2}{|l|}{$\begin{array}{l}\text { Validation cohort } \\
(n=113)\end{array}$} \\
\hline & $\begin{array}{l}\text { hazard ratio } \\
\text { Exp(B) }(95 \% \mathrm{CI})\end{array}$ & $p$ & $\begin{array}{l}\text { hazard ratio } \\
\text { Exp(B) }(95 \% \text { CI) }\end{array}$ & $p$ \\
\hline \multicolumn{5}{|c|}{ Child-Turcotte-Pugh stage } \\
\hline No LCI & - & $0.516^{*}$ & - & $0.058 *$ \\
\hline A & $0.78(0.40-1.55)$ & 0.482 & $0.32(0.11-0.90)$ & 0.030 \\
\hline B & $0.68(0.36-1.31)$ & 0.252 & $0.32(0.12-0.88)$ & 0.027 \\
\hline $\mathrm{C}$ & - & - & & \\
\hline \multicolumn{5}{|l|}{ ECOG score } \\
\hline 0 & - & $<0.001 *$ & - & 0.849 \\
\hline 1 & $2.02(1.23-3.30)$ & 0.005 & $1.19(0.65-2.17)$ & 0.568 \\
\hline 2 & $9.05(3.47-23.60)$ & $<0.001$ & $\mathrm{NR}$ & 0.984 \\
\hline 3 & NR & & & \\
\hline 4 & & & & \\
\hline \multicolumn{5}{|c|}{ Portal thrombosis } \\
\hline No & - & 0.002 & - & 0.029 \\
\hline Yes & $2.01(1.29-3.13)$ & & $1.19(0.65-2.17)$ & \\
\hline \multicolumn{5}{|c|}{ Extrahepatic HCC metastasis } \\
\hline No & - & 0.638 & - & 0.630 \\
\hline Yes & $1.13(0.68-1.88)$ & & $1.20(0.58-2.49)$ & \\
\hline \multicolumn{5}{|c|}{ Etiology of liver disease } \\
\hline Non-viral & - & 0.064 & - & 0.025 \\
\hline Viral & $0.64(0.46-1.02)$ & & $2.27(1.11-4.62)$ & \\
\hline \multicolumn{5}{|c|}{ Oncologic treatment before sorafenib } \\
\hline No & - & 0.976 & - & 0.828 \\
\hline Yes & $1.01(0.65-1.56)$ & & $0.94(0.53-1.66)$ & \\
\hline \multicolumn{5}{|l|}{ Total bilirubin } \\
\hline$\leq 1.2 \mathrm{~g} / \mathrm{dL}$ & - & 0.320 & - & 0.009 \\
\hline$>1.2 \mathrm{~g} / \mathrm{dL}$ & $1.53(0.86-2.71)$ & & $2.64(1.27-5.50)$ & \\
\hline \multicolumn{5}{|l|}{ Thrombocytes } \\
\hline$<100 / \mathrm{nL}$ & - & 0.321 & - & 0.940 \\
\hline$\geq 100 / \mathrm{nL}$ & $0.72(0.38-1.38)$ & & $1.03(0.46-2.31)$ & \\
\hline \multicolumn{5}{|l|}{ NLR } \\
\hline$<5$ & - & 0.148 & - & 0.297 \\
\hline$\geq 5$ & $1.53(0.86-2.71)$ & & $1.54(0.69-3.43)$ & \\
\hline \multicolumn{5}{|l|}{ PLR } \\
\hline$<150$ & - & $0.987^{*}$ & - & $0.103^{*}$ \\
\hline $150-300$ & $1.04(0.619-1.74)$ & 0.889 & $0.62(0.26-1.47)$ & 0.275 \\
\hline$>300$ & $1.05(0.52-2.12)$ & 0.885 & $1.78(0.54-5.87)$ & 0.345 \\
\hline \multicolumn{5}{|l|}{ CAR } \\
\hline$<0.37$ & - & $<0.001$ & - & 0.001 \\
\hline$\geq 0.37$ & $2.42(1.48-3.95)$ & & $3.59(1.69-7.65)$ & \\
\hline \multicolumn{5}{|l|}{ GPS } \\
\hline 0 & - & $0.010 *$ & - & $<0.001 *$ \\
\hline 1 & $1.07(0.54-2.11)$ & 0.847 & $6.08(2.47-15.00)$ & $<0.001$ \\
\hline 2 & $2.18(1.08-4.38)$ & 0.029 & $8.29(3.00-22.91)$ & $<0.001$ \\
\hline
\end{tabular}




\section{Liver Cancer}

\begin{tabular}{l|l}
\hline Liver Cancer 2019:8:387-402 \\
\hline DOI: 10.1159/000492628 & $\begin{array}{l}\text { ○ 2018 S. Karger AG, Basel } \\
\text { www.karger.com/lic }\end{array}$ \\
\hline
\end{tabular}

Sprinzl et al.: Extended Prognostic Inflammatory Score for HCC

Table 4 (continued)

\begin{tabular}{|c|c|c|c|c|}
\hline \multirow[t]{2}{*}{ Variable } & \multicolumn{2}{|l|}{$\begin{array}{l}\text { Exploration cohort } \\
(n=120)\end{array}$} & \multicolumn{2}{|l|}{$\begin{array}{l}\text { Validation cohort } \\
(n=113)\end{array}$} \\
\hline & $\begin{array}{l}\text { hazard ratio } \\
\text { Exp(B) }(95 \% \mathrm{CI})\end{array}$ & $p$ & $\begin{array}{l}\text { hazard ratio } \\
\operatorname{Exp(B)~}(95 \% \mathrm{CI})\end{array}$ & $p$ \\
\hline \multicolumn{5}{|l|}{ mGPS } \\
\hline 0 & - & $0.004 *$ & - & $0.001 *$ \\
\hline 1 & $1.66(0.84-3.26)$ & 0.143 & $3.57(1.45-8.77)$ & 0.005 \\
\hline 2 & $2.45(1.44-4.17)$ & 0.001 & $5.48(2.12-14.15)$ & 0.000 \\
\hline \multicolumn{5}{|l|}{ GPS-EP } \\
\hline 0 & - & $0.021 *$ & - & 0.001 \\
\hline 1 & $1.55(0.59-4.08)$ & 0.376 & $0.98(0.13-7.11)$ & 0.981 \\
\hline 2 & $2.74(0.97-7.81)$ & 0.058 & $1.69(0.27-10.77)$ & 0.579 \\
\hline 3 & $3.94(0.99-9.29)$ & 0.051 & $6.45(0.95-43.55)$ & 0.056 \\
\hline 4 & 7.78 (1.91-31.68) & 0.004 & $13.61(1.7-109.47)$ & 0.014 \\
\hline 5 & $24.03(2.68-215.36)$ & 0.004 & NR & \\
\hline 6 & - & & - & \\
\hline
\end{tabular}

PLR, platelet to lymphocyte ratio; NLR, neutrophil to leukocyte ratio; CAR, C-reactive protein to albumin ratio; GPS, Glasgow prognostic score; mGPS, modified Glasgow prognostic score; GPS-EP, ECOG/portal thrombosis-extended modified Glasgow prognosis score; NR, not rated. Baseline variables were assessed at the time point of sorafenib treatment initiation in BCLC-C stage HCC patients for both cohorts as indicated. Multivariable Cox regression included covariate analysis of Child-Turcotte-Pugh stage, ECOG score, portal thrombosis, extrahepatic metastasis, oncological pre-treatment, viral etiology, hyperbilirubinemia, thrombocytopenia, PLR and NLR. * Overall $p$ value across all strata.

Due to the long inclusion period, we also assessed patients receiving sorafenib at late HCC stages prior to introduction of more restrictive HCC treatment guidelines [32]. In particular, we had included a high proportion of patients with CTP-B cirrhosis before the limited benefit of sorafenib in patients with impaired liver function was acknowledged [38]. This resulted in a fairly low median OS of 6.2-8.2 months in our cohort, compared to other published HCC studies predominantly investigating sorafenib in HCC patients with compensated cirrhosis [36, 37]. In addition, different proportions of liver cirrhosis and portal thrombosis could also explain disparities of OS and PFS between the exploration and validation cohort.

For this reason, we selected HCC patients without CTP stage B cirrhosis to adhere with current treatment practice. Following this selection, we were still able to identify a highly significant correlation between inflammatory scores (e.g., CAR, GPS, mGPS and GPS-EP) and survival. Therefore, the association of inflammation with survival did not only depend on underlying liver cirrhosis. In fact the correlation of inflammatory scores with treatment response (PFS) supports a direct effect of inflammation on tumor sensitivity to sorafenib. The mechanisms behind an inflammation-driven resistance against sorafenib are not well defined, but experimental data suggest hypoxia and NF- $\mathrm{KB}$ induction as potential factors [39].

Although we showed a reproducible prediction of 12-month survival by known inflammatory scores, a different study identified higher ROC-AUC for CAR $(0.863,95 \%$ CI: $0.803-$ 0.923), GPS (0.794, 95\% CI: 0.710-0.878) and mGPS (0.776, 95\% CI: 0.682-0.869) [24]. We speculate that cohort composition and population-specific physical conditions are responsible for these divergent results. 


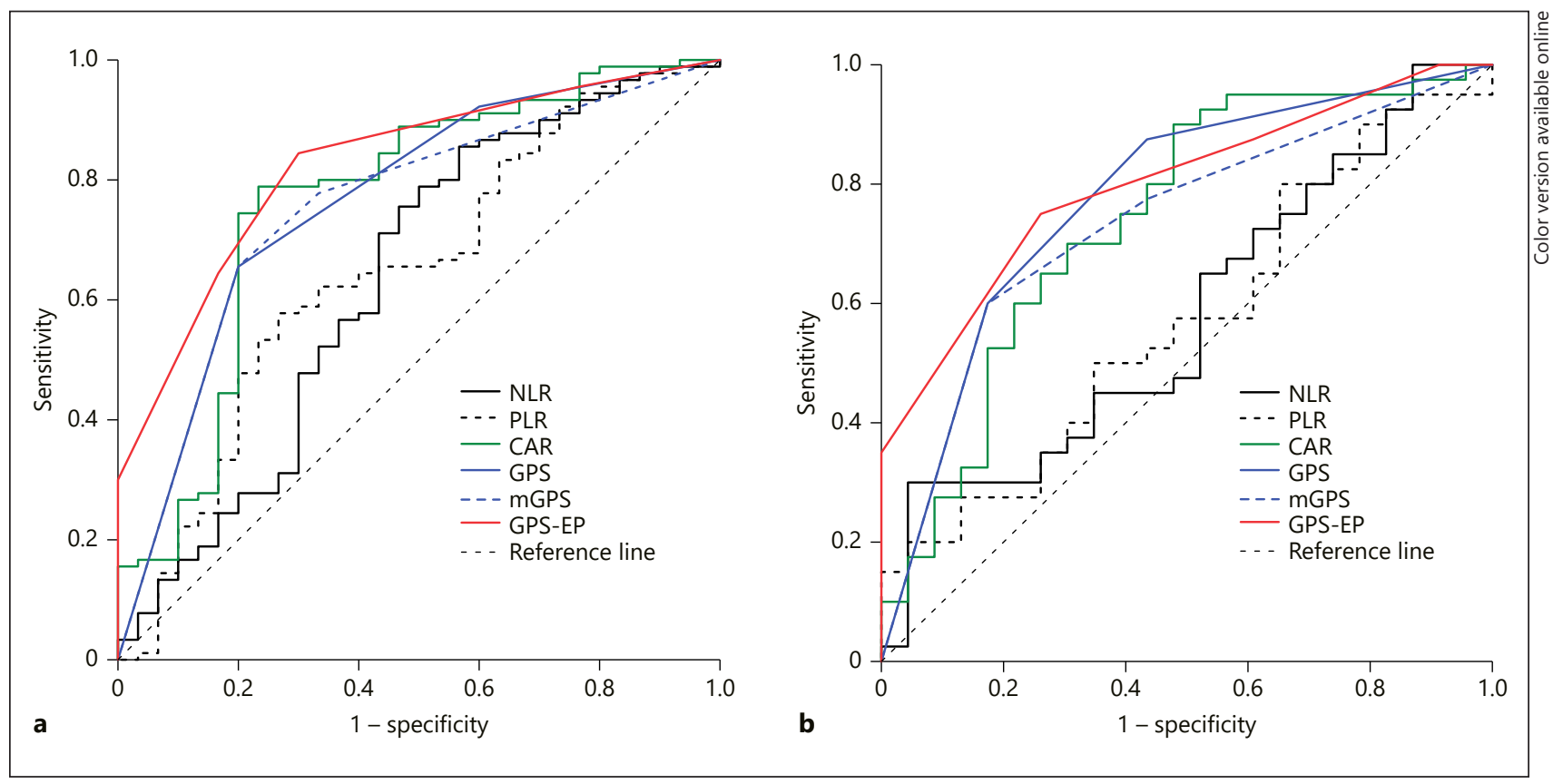

Fig. 2. Comparative ROC analysis according to inflammatory scores. AUC-ROC analysis was performed for the exploration cohort $(n=120)$ (a) and the validation cohort $(n=113)$ (b) receiving sorafenib treatment for BCLC-C stage HCC. ROC values were assessed for the 12-month survival according to inflammatory scores defined by platelet to lymphocyte ratios (PLR), neutrophil to leukocyte ratios (NLR), C-reactive protein to albumin ratios (CAR), the Glasgow prognostic score (GPS), modified GPS (mGPS) and ECOG/portal thrombosis-extended Glasgow prognosis score (GPS-EP). $p$ values were determined according to DeLong et al. [34] at a significance level of $p \leq 0.05$.

The GPS-EP score could overcome cohort heterogeneity, as it integrates detrimental consequences of inflammation and clinical performance. In the context of HCC disease, GPS-EP seems superior compared to pure inflammatory scores.

Interestingly, ECOG score and portal thrombosis are mechanistically connected to chronic inflammation, although they represent independent survival risk factors. ECOG score is linked to frailty caused by reduced muscle strength and sarcopenia, which could result from inflammation during end-stage liver disease [40, 41]. Portal vein thrombosis, which is typically caused by malignant vascular infiltration, may partially result from systemic inflammation in HCC patients with underlying liver cirrhosis. Particularly chronic endotoxemia in liver cirrhosis drives coagulopathy which correlates with tissue factor activation [42] and elevated von Willebrand factor levels in patients with portal thrombosis [43]. It is very important that GPS, ECOG score and portal thrombosis are well-defined categories, which could be obtained during routine laboratory, clinical and radiological assessment. In addition, the utilized GPS-EP scoring components are not modified and can easily be calculated. This simple risk stratification was even superior to a modified score, which incorporated the same categories following a data-driven risk weighting (see online suppl. Table 5a/b).

Despite its basic composition without any optimized cut-off, GPS-EP could exclude some HCC patients from non-beneficial systemic sorafenib therapy. Following a restrictive GPS-EP cut-off ( $>3$ points, at $89 \%$ specificity) for the prediction of 3-month survival, we would have identified 17 patients without relevant treatment response to sorafenib. 
Sprinzl et al.: Extended Prognostic Inflammatory Score for HCC

We are aware that the selection of European cohorts and study site-specific treatment strategies before sorafenib could have biased our observations. Facing these limitations, we encourage further evaluation of our findings in independent patient populations with different ethnicity as well as with other underlying liver disease and therapeutic background.

\section{Acknowledgements}

We thank Mara Doerken for the critical review of the manuscript. Data presented in this publication are partially derived from the doctoral thesis of Marie-Luise Seib.

\section{Disclosure Statement}

M.F.S., M.-L.S., S.K., J.U.M., J.W.- M., C.D. and H.L. declare no conflict of interest regarding the content of this manuscript. M.-A.W., A.W. received travel and lecture fees from Bayer Healthcare, P.R.G. is consultant and speaker bureau member of Bayer Healthcare.

\section{Funding Sources}

The study was funded by institutional research funds of the University Medical Center, Johannes Gutenberg University, Mainz, offered to A.W. and M.F.S.

\section{Author Contributions}

M.F.S. and A.W. provided study concept, performed data acquisition data analysis and wrote the manuscript. S.K., M.M.K., M.P. and M.-L.S. provided data acquisition and data analysis. J.W.-M., J.U.M. and M.-A.W. contributed to clinical follow up and critical discussion and reviewed the manuscript. D.Z. and G.T. provided statistical analysis. H.L., C.D., A.V. and P.R.G. provided essential infrastructure to perform this study and critical manuscript discussion.

\section{References}

1 Zhu XD, Zhang JB, Zhuang PY, Zhu HG, Zhang W, Xiong YQ, et al. High expression of macrophage colony-stimulating factor in peritumoral liver tissue is associated with poor survival after curative resection of hepatocellular carcinoma. J Clin Oncol. 2008 Jun;26(16):2707-16.

2 Ding T, Xu J, Wang F, Shi M, Zhang Y, Li SP, et al. High tumor-infiltrating macrophage density predicts poor prognosis in patients with primary hepatocellular carcinoma after resection. Hum Pathol. 2009 Mar; 40(3): 381-9.

3 Waidmann O, Köberle V, Bettinger D, Trojan J, Zeuzem S, Schultheiß M, et al. Diagnostic and prognostic significance of cell death and macrophage activation markers in patients with hepatocellular carcinoma. J Hepatol. 2013 Oct;59(4):769-79.

4 Singel KL, Segal BH. Neutrophils in the tumor microenvironment: trying to heal the wound that cannot heal. Immunol Rev. 2016 Sep;273(1):329-43.

5 Zhou SL, Zhou ZJ, Hu ZQ, Huang XW, Wang Z, Chen EB, Fan J, Cao Y, Dai Z, Zhou J: Tumor-Associated Neutrophils Recruit Macrophages and T-Regulatory Cells to Promote Progression of Hepatocellular Carcinoma and Resistance to Sorafenib. Gastroenterology 2016;150:1646-1658 e1617.

6 Yamanaka T, Matsumoto S, Teramukai S, Ishiwata R, Nagai Y, Fukushima M. The baseline ratio of neutrophils to lymphocytes is associated with patient prognosis in advanced gastric cancer. Oncology. 2007;73(3-4):21520.

7 Cho H, Hur HW, Kim SW, Kim SH, Kim JH, Kim YT, et al. Pre-treatment neutrophil to lymphocyte ratio is elevated in epithelial ovarian cancer and predicts survival after treatment. Cancer Immunol Immunother. 2009 Jan;58(1):15-23.

8 Halazun KJ, Aldoori A, Malik HZ, Al-Mukhtar A, Prasad KR, Toogood GJ, Lodge JP: Elevated preoperative neutrophil to lymphocyte ratio predicts survival following hepatic resection for colorectal liver metastases. Eur J Surg Oncol 2008;34:55-60. https://doi.org/10.1016/j.ejso.2007.02.014. 
Sprinzl et al.: Extended Prognostic Inflammatory Score for HCC

9 Kushner I, Feldmann G. Control of the acute phase response. Demonstration of C-reactive protein synthesis and secretion by hepatocytes during acute inflammation in the rabbit. J Exp Med. 1978 Aug;148(2):466-77.

10 Hurlimann J, Thorbecke GJ, Hochwald GM. The liver as the site of C-reactive protein formation. J Exp Med. 1966 Feb;123(2):365-78.

11 Patel DN, King CA, Bailey SR, Holt JW, Venkatachalam K, Agrawal A, et al. Interleukin-17 stimulates C-reactive protein expression in hepatocytes and smooth muscle cells via p38 MAPK and ERK1/2-dependent NF-kappaB and C/EBPbeta activation. J Biol Chem. 2007 Sep;282(37):27229-38.

12 Kramer F, Torzewski J, Kamenz J, Veit K, Hombach V, Dedio J, et al. Interleukin-1beta stimulates acute phase response and C-reactive protein synthesis by inducing an NFkappaB- and C/EBPbeta-dependent autocrine interleukin-6 loop. Mol Immunol. 2008 May;45(9):2678-89.

13 Kino T, Rice KC, Chrousos GP. The PPARdelta agonist GW501516 suppresses interleukin-6-mediated hepatocyte acute phase reaction via STAT3 inhibition. Eur J Clin Invest. 2007 May;37(5):425-33.

14 Yoshikawa H, Matsubara K, Qian GS, Jackson P, Groopman JD, Manning JE, et al. SOCS-1, a negative regulator of the JAK/STAT pathway, is silenced by methylation in human hepatocellular carcinoma and shows growthsuppression activity. Nat Genet. 2001 May;28(1):29-35.

15 Pikarsky E, Porat RM, Stein I, Abramovitch R, Amit S, Kasem S, et al. NF-kappaB functions as a tumour promoter in inflammation-associated cancer. Nature. 2004 Sep;431(7007):461-6.

16 He G, Karin M. NF-кB and STAT3 - key players in liver inflammation and cancer. Cell Res. 2011 Jan;21(1): 159-68.

17 Lee H, Deng J, Kujawski M, Yang C, Liu Y, Herrmann A, et al. STAT3-induced S1PR1 expression is crucial for persistent STAT3 activation in tumors. Nat Med. 2010 Dec;16(12):1421-8.

18 Kortylewski M, Xin H, Kujawski M, Lee H, Liu Y, Harris T, et al. Regulation of the IL-23 and IL-12 balance by Stat3 signaling in the tumor microenvironment. Cancer Cell. 2009 Feb;15(2):114-23.

19 Proctor MJ, Morrison DS, Talwar D, Balmer SM, O’Reilly DS, Foulis AK, et al. An inflammation-based prognostic score (mGPS) predicts cancer survival independent of tumour site: a Glasgow Inflammation Outcome Study. Br J Cancer. 2011 Feb;104(4):726-34.

20 Fan W, Zhang Y, Wang Y, Yao X, Yang J, Li J. Neutrophil-to-lymphocyte and platelet-to-lymphocyte ratios as predictors of survival and metastasis for recurrent hepatocellular carcinoma after transarterial chemoembolization. PLoS One. 2015 Mar;10(3):e0119312.

21 Chen TM, Lin CC, Huang PT, Wen CF. Neutrophil-to-lymphocyte ratio associated with mortality in early hepatocellular carcinoma patients after radiofrequency ablation. J Gastroenterol Hepatol. 2012 Mar;27(3):553-61.

22 Motomura T, Shirabe K, Mano Y, Muto J, Toshima T, Umemoto Y, et al. Neutrophil-lymphocyte ratio reflects hepatocellular carcinoma recurrence after liver transplantation via inflammatory microenvironment. J Hepatol. 2013 Jan;58(1):58-64.

23 Gomez D, Farid S, Malik HZ, Young AL, Toogood GJ, Lodge JP, et al. Preoperative neutrophil-to-lymphocyte ratio as a prognostic predictor after curative resection for hepatocellular carcinoma. World J Surg. 2008 Aug; 32(8):1757-62.

24 Kinoshita A, Onoda H, Imai N, Iwaku A, Oishi M, Tanaka K, et al. The C-reactive protein/albumin ratio, a novel inflammation-based prognostic score, predicts outcomes in patients with hepatocellular carcinoma. Ann Surg Oncol. 2015 Mar;22(3):803-10.

25 Pinato DJ, Stebbing J, Ishizuka M, Khan SA, Wasan HS, North BV, et al. A novel and validated prognostic index in hepatocellular carcinoma: the inflammation based index (IBI). J Hepatol. 2012 Nov;57(5):1013-20.

26 Yamamura K, Sugimoto H, Kanda M, Yamada S, Nomoto S, Nakayama G, et al. Comparison of inflammationbased prognostic scores as predictors of tumor recurrence in patients with hepatocellular carcinoma after curative resection. J Hepatobiliary Pancreat Sci. 2014 Sep;21(9):682-8.

27 Hashimoto K, Ikeda Y, Korenaga D, Tanoue K, Hamatake M, Kawasaki K, et al. The impact of preoperative serum C-reactive protein on the prognosis of patients with hepatocellular carcinoma. Cancer. 2005 May; 103(9):1856-64.

28 Nakanishi H, Kurosaki M, Tsuchiya K, Yasui Y, Higuchi M, Yoshida T, et al. Novel Pretreatment Scoring Incorporating C-reactive Protein to Predict Overall Survival in Advanced Hepatocellular Carcinoma with Sorafenib Treatment. Liver Cancer. 2016 Oct;5(4):257-68.

29 Bruix J, Cheng AL, Meinhardt G, Nakajima K, De Sanctis Y, Llovet J. Prognostic factors and predictors of sorafenib benefit in patients with hepatocellular carcinoma: analysis of two phase III studies. J Hepatol. 2017 Nov;67(5):999-1008.

30 Oken MM, Creech RH, Tormey DC, Horton J, Davis TE, McFadden ET, et al. Toxicity and response criteria of the Eastern Cooperative Oncology Group. Am J Clin Oncol. 1982 Dec;5(6):649-55.

31 Pugh RN, Murray-Lyon IM, Dawson JL, Pietroni MC, Williams R. Transection of the oesophagus for bleeding oesophageal varices. Br J Surg. 1973 Aug;60(8):646-9.

32 European Association For The Study of The L. European Organisation For R, Treatment Of C: EASL-EORTC clinical practice guidelines: management of hepatocellular carcinoma. J Hepatol. 2012;56(4):908-43.

33 Weinmann A, Koch S, Sprinzl M, Kloeckner R, Schulze-Bergkamen H, Duber C, Lang H, Otto G, Worns MA, Galle PR: Survival analysis of proposed BCLC-B subgroups in hepatocellular carcinoma patients. Liver Int 2015;35: 591-600. https://doi.org/10.1111/liv.12696.

34 DeLong ER, DeLong DM, Clarke-Pearson DL. Comparing the areas under two or more correlated receiver operating characteristic curves: a nonparametric approach. Biometrics. 1988 Sep;44(3):837-45. 
35 Kinoshita A, Onoda H, Imai N, Iwaku A, Oishi M, Fushiya N, et al. Comparison of the prognostic value of inflammation-based prognostic scores in patients with hepatocellular carcinoma. Br J Cancer. 2012 Sep;107(6): 988-93.

36 Llovet JM, Ricci S, Mazzaferro V, Hilgard P, Gane E, Blanc JF, et al.; SHARP Investigators Study Group. Sorafenib in advanced hepatocellular carcinoma. N Engl J Med. 2008 Jul;359(4):378-90.

37 Cheng AL, Kang YK, Chen Z, Tsao CJ, Qin S, Kim JS, et al. Efficacy and safety of sorafenib in patients in the AsiaPacific region with advanced hepatocellular carcinoma: a phase III randomised, double-blind, placebocontrolled trial. Lancet Oncol. 2009 Jan;10(1):25-34.

38 Wörns MA, Weinmann A, Pfingst K, Schulte-Sasse C, Messow CM, Schulze-Bergkamen H, et al. Safety and efficacy of sorafenib in patients with advanced hepatocellular carcinoma in consideration of concomitant stage of liver cirrhosis. J Clin Gastroenterol. 2009 May-Jun;43(5):489-95.

39 Liang Y, Zheng T, Song R, Wang J, Yin D, Wang L, et al. Hypoxia-mediated sorafenib resistance can be overcome by EF24 through Von Hippel-Lindau tumor suppressor-dependent HIF-1 $\alpha$ inhibition in hepatocellular carcinoma. Hepatology. 2013 May;57(5):1847-57.

40 Meza-Junco J, Montano-Loza AJ, Baracos VE, Prado CM, Bain VG, Beaumont C, et al. Sarcopenia as a prognostic index of nutritional status in concurrent cirrhosis and hepatocellular carcinoma. J Clin Gastroenterol. 2013 Nov-Dec;47(10):861-70.

41 Schaap LA, Pluijm SM, Deeg DJ, Visser M: Inflammatory markers and loss of muscle mass (sarcopenia) and strength. Am J Med 2006;119:526 e529-517.

42 Saliola M, Lorenzet R, Ferro D, Basili S, Caroselli C, Santo AD, et al. Enhanced expression of monocyte tissue factor in patients with liver cirrhosis. Gut. 1998 Sep;43(3):428-32.

43 Ferlitsch M, Reiberger T, Hoke M, Salzl P, Schwengerer B, Ulbrich G, et al. von Willebrand factor as new noninvasive predictor of portal hypertension, decompensation and mortality in patients with liver cirrhosis. Hepatology. 2012 Oct;56(4):1439-47. 